tive studies, in renal artery stenosis and stroke. In renal artery stenosis injudicious lowering of blood pressure long term can decrease renal perfusion pressure with a resulting loss of renal function " and possible death. ${ }^{12}$ Likewise, long term antihypertensive treatment in patients with cerebrovascular atheroma can cause a critical fall in cerebral blood flow, ${ }^{12}$ which may be accompanied by neurologica symptoms and stroke. ${ }^{14}$ Raising the blood pressure in such cases can abolish transient ischaemic attacks, ${ }^{14}$ as occurred in the case reported by $\mathrm{Dr}$ Mark Oliver.'

It is difficult to understand why Dr Waller and colleagues and Drs Coope and Warrender are so resistant to the concept that in hypertensive patients with severe atheromatous narrowing of their coronary arteries, particularly in the presence of left ventricular hypertrophy, autoregulatory processes are impaired owing to a fall in coronary flow reserve. They prefer instead an explanation for the J curve for which apparently no evidence exists (to my knowledge) in the database of Dr Waller and colleagues.' Their graph of the coronary mortality versus diastolic blood pressure relation in ischaemic and non-ischaemic patients shows a clear J curve in ischaemic patients but only a blurred picture for the non-ischaemic patients.

As difficult to understand is the reluctance of $\mathrm{Dr}$ Waller and colleagues to countenance a simple, minor change in clinical practice in treating hypertensive patients with myocardial ischaemia (that is, a goal diastolic blood pressure (phase $\mathrm{V}$ ) of $85-90 \mathrm{~mm} \mathrm{Hg}$ instead of less than $85 \mathrm{~mm} \mathrm{Hg}$ ), which would almost certainly not harm the patien in terms of preventing stroke $\mathrm{e}^{3}$ and might prevent death from myocardial infarction. A prospective study in well characterised hypertensive patients to confirm the retrospective observations of at least 10 studies would, of course, be welcome.

Drs Eoin O'Brien and Kevin O'Malley remind us $^{16}$ that excessive lowering of nocturnal blood pressure might cause subendocardial ischaemia, as recently proposed by Floras, ${ }^{1:}$ and contribute to the J curve relation between diastolic blood pressure and myocardial infarction. Even "dippers," however, have hypertension at nigh (with mean nocturnal blood pressures similar to mean daytime blood pressures of normotensive subjects), " and nocturnal blood pressure seems to be an excellent positive predictor of organ damage (G Mancia, personal communication). Dr Morris Brown correctly points out that hypertension itsel may not be the cause of increased coronary risk, and a broader view should be taken incorporating other risk factors. ${ }^{19}$

Dr Lennart Hansson has suggested that the $J$ point could lie anywhere between 0 and $89-90 \mathrm{~mm} \mathrm{Hg}{ }^{2 .}$ "This view is surprising as three studies that have looked at two or more points below the J point have shown that the "step up" in the incidence of myocardial infarction occurs between 84 and $90 \mathrm{~mm} \mathrm{Hg}$ diastolic blood pressure (phase V). To be more precise than this would require data on a massive number of end points. Dr Hansson's lack of concern about the mechanism of the J curve could lead to a flawed prospective study on an inappropriately low risk hypertensive population, a trap that he and his coworkers might well have already fallen into.

J M CRUICKSHANK

ICI Pharmaceuticals

Macclesfield,

Cheshire SK 10 4TG

1 Waller PC, Isles CG, McInnes GT. Coronary flow reserve and the J curve. Br Med F 1988;297:1606. (17 December.

2 Coope J, Warrender TS. Coronary flow reserve and the J curve. B Med f 1988;297:1607. (17 December.)

3 Cruickshank JM. Coronary flow reserve and the J curve relation between diastolic blood pressure and mvocardial infarction. Br.Med F 1988:297:1227-30.

4 Coope J. Heart attacks and lowered blood pressure. Lancet 1987; i:865-6.

5 Coope J, Warrender TS. Lowering blood pressure. Lancet $1987 ; \mathrm{i}: 1380$.

6 Waller PC, Isles CG, Lever AF, McInnes GT. How far to lower blood pressure? Lancet 1987;ii:969.
Cruickshank JM, Thorp JM, Zacharias FJ. Heart attacks and lowering of blood pressure. Lancet i:1154.

8 Cruickshank JM. Thorp JM, Zacharias FJ. Lowering blood pressure. Lancet 1987;ii:223

Cruickshank JM, Thorp JM, Zacharias FJ. How far to lower blood pressure? Lancet 1987;ii:695.

10 Cooper SP. Hardy RJ, Labarthe DR, et al. The relation between degree of blood pressure reduction and mortality among hypertensives in the hypertension detection and follow-up program. A 7 F Eipidemiol 1988;127:387-403.

11 Hricik DE, Browning PJ, Kopelman R, Goorno WE, Madias VE, Drau VJ. Captopril-induced functional renal insuffi-

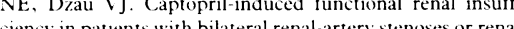
cency inatents uith bilateral renal-artern stenoses or renaartery stencs $308.373-6$

12 Speirs CJ, Dollery CT, Inman WHW, Rawson NSB, Wilton LV. Postmarketing surveillance of enalapril. II. Investigation of the potential role of enalapril in deaths with renal failure.

13 Bertel O, Marx BE, Conen D. Effects of antihypertensive treatment on cerebral perfusion. Am 7 .Med 1987;82 supp $3 \mathrm{~B}: 29-36$

14 Strandgaard S. Autoregulation of cerebral hlood flow in hipertensive patients. The modifying influence of prolonged antihypertensive treatment on the tolerance of acute, drug induced hypotension. Circulation 1976;53:720-7.

15 Oliver M. Coronary flow reserve and the J curve. Br Med 7 1988;27:1607. (17 December.)

$16 \mathrm{O}^{\prime}$ Brien E, O'Malley $\mathrm{K}$. Coronary flow reserve and the J curve. Br.Med F 1988:297:1607. 17 December.

17 Floras JS. Antihypertensive treatment, myocardial infarction, and nocturnal myecardial ischaemia. Lancet 1988;ii:994-6.

18 Mancia G, Ferrari A, Gregorini L, et al. Blood pressure and heart rate variabilities in normotensive and hypertensive human beings. Circ Re's 1983;53:96-104.

19 Brown MJ. Coronary flow reserve and the J curve. Br Med $\mathcal{F}$ 1988:297:1607-8. (17 December.

20 Hansson L. J curve relation between diastolic blood pressure and myocardial infarction. Br Med $\mathcal{f}$ 1989;298:52. January.

\section{Time to let the patient speak}

SIR,-Having read Dr J N Blau's article,' we thought that patients would take less time to describe their presenting problem in general practice than in a hospital outpatient clinic. We (a trainer and a trainee) therefore decided that we would each record the length of the initial speech of 50 consecutive patients seen in normal surgery hours in response to a general opening question such as, "What can I do for you today?"

The results showed that of 100 patients seen, only one patient managed to speak for more than two minutes and $87 \%$ spoke for less than a minute. The mean length of speech was 35 seconds, the mean value for the trainee being 27 seconds and that for the trainer being 45 seconds, which probably reflects the different age groups of the patients and their type of complaint $-64 \%$ of the trainee's patients were under 30 compared with only $30 \%$ of the trainer's patients

Dr Blau's patients spoke on average for 1 minute and 40 seconds. This difference is not surprising: for most patients this will be their first encounter with the specialist, who has no previous knowledge of them. They will often present a well rehearsed speech covering all the details of their complaint. In general practice the patient and some aspects of the presenting complaint are usually known to the doctor or the patient may be returning to discuss test results or request a service. In our study the longest initial speeches recorded were for problems such as depression, general malaise, or requests for advice.

Criticism is sometimes levelled at general practitioners for not giving their patients sufficient time. It would seem from this brief study that most of our patients do not require much time to state their problem. Allowing them to do this

Length of speaking by 100 patients uninterrupted should not increase consultation times but might increase patient satisfaction-it may at least be worth a try.

B OLSBURGH

DIANA M JELLEY

Whitley Bay

Tyne and Wear NE26 2ND)

I Blau JN. Time to let the patient speak. Br. Hed f 1989:298:39. (7) January.

\section{Aluminium accumulation and immunosuppression}

SIR,-Dr K P Nordal and colleagues suggested that the accumulation of aluminium in transiliac bone was associated with a reduction in the incidence of episodes of renal allograft rejection.' We have previously commented on patients with subclinical or mild forms of aluminium encephalopathy who became frankly encephalopathic after successful renal allograft transplantation' owing to the mobilisation of aluminium in tissue. ${ }^{3}$ Interestingly, we noted that these patients had an appreciable reduction in the number of acute episodes of renal allograft rejection but had a high mortality due to infection.

We subsequently followed up 58 patients after successful renal allograft transplantation (mean follow up 11.8 months, range 6-15). Urinary aluminium excretion was used as a marker of tissue aluminium accumulation, as we think that this best reflects the amount of aluminium that is freely available for mobilisation. The total aluminium content includes precipitated aluminium complexes that cannot be mobilised. The patients were divided into two groups on the basis of the number of rejection episodes diagnosed on Tru-Cut graft biopsy, fine needle aspiration cytology, and trough concentrations of cyclosporin. Twenty eight patients had one or no rejection episodes and 30 had two or more. The two groups did not differ significantly in age or sex, the type or duration of dialysis, or the prescription of phosphate binders containing aluminium. The median daily urinary excretion of aluminium was greater in the group with one or no rejection episodes than in the group with two or more during the first year after transplantation (table). Renal function as assessed

Urinary excretion of aluminium ( $\mu$ mol/24 h) after successful renal allograft transplantation. Values are medians (ranges)

\begin{tabular}{ccc}
\hline \multirow{2}{*}{$\begin{array}{c}\text { Time after } \\
\text { transplantation } \\
\text { (months) }\end{array}$} & \multicolumn{2}{c}{ Rejection episodes } \\
\cline { 2 - 3 } & 0 or 1 & $\geqslant 2$ \\
\hline $0-3$ & $2 \cdot 8(0 \cdot 6-25 \cdot 1)$ & $1 \cdot 8(0 \cdot 2-6 \cdot 6)^{\star \star}$ \\
$4-6$ & $2 \cdot 5(0 \cdot 7-14 \cdot 3)$ & $1 \cdot 4(0 \cdot 3-6 \cdot 2)^{\star}$ \\
$7-9$ & $1 \cdot 9(0 \cdot 9-12 \cdot 4)$ & $1 \cdot 1(0 \cdot 5-3 \cdot 1)^{\star}$ \\
$10-12$ & $1 \cdot 8(0 \cdot 5-9 \cdot 4)$ & $1 \cdot 0(0 \cdot 1-3 \cdot 3)^{\star}$ \\
\hline
\end{tabular}

${ }^{\star} \mathrm{p}<0 \cdot 01,{ }^{\star \star} \mathrm{p}<0 \cdot 001$, Mann-Whitney U test.

by measurements of 24 hour creatinine clearance was not significantly different between the groups. These data support the argument that the mobilisation of aluminium after successful renal allograft transplantation affects the immune response and results in fewer acute episodes of allograft rejection.

We have also reported that bacterial infections may result in a release of aluminium from tissue 
stores and that those patients with the greatest aluminium burden had an increased mortality after infection. ${ }^{+}$As most aluminium given to patients with acute renal failure is taken up by soft tissues, including the liver and spleen, but not by bones and thus enters the reticuloendothelial system it is not surprising that aluminium may have an immunomodulatory role. Although this may be of benefit to the recipient of a renal transplant, aluminium accumulation should be avoided in patients with acute renal failure, in whom sepsis remains a major cause of both morbidity and mortality.

$$
\begin{array}{rr}
\text { A DAVENPORT } & \text { C TOOTHILL } \\
\text { A M DAVISON } & \text { K E NEWTON } \\
\text { E J WILL } & \text { G R GILES }
\end{array}
$$

St James's University Hospital,

Leeds LS9 7TF

1 Nordal KP, Dahl E, Albrechtsen D, et al. Aluminium accumulation and immunosuppressive effect in recipients of kidney transplants. Br Med f 1988;297:1581-9. (17 December.)

2 Davison AM, Giles GR. The effect of transplantation on dialysis dementia. Proceedings of the European Dialysis and Transplant Association 1979;6:407-12.

3 Davenport A, Will EJ, Newton KE, et al. Aluminium excretion after successful renal allograft transplantation. Ann Clin Biochem 1988;25 (suppl 1):S45-6.

4 Davenport A, Williams PS, Roberts NB, Bone JM. Sepsis: a cause of aluminium release from tissue stores associated with acute neurological dysfunction and mortality. Clin Nephrol 1988;30:48-51.

5 Roberts NB, Davenport A. Aluminium bone disease. Br Med $\mathcal{f}$ 1987:295:1209-10.

6 Davenport A, Roberts NB. The accumulation of aluminium in patients with acute renal failure. Nephron (in press).

\section{Computerised updating of clinical summaries}

SIR, - Dr Anthony Hopkins takes us to task for using standard text to produce hospital discharge summaries and says that because of its rigidity our approach is intellectually flawed. ' He thinks that word processing techniques should be used to remind hospital doctors about what they should be telling the general practitioner and that they should then do so in free text. But our editing is often done in exactly this way - by referring to the standard text and then producing a personal version based on it. Dr Hopkins has read far too much into our simple example, which was chosen to illustrate the principle of the editing process.

The system is flexible, but it also encourages intellectual discipline: each action has to be explained with a diagnosis (or a differential diagnosis), which has to be justified with some indication of the evidence. When there is no clear diagnosis this is made obvious. But a covering letter is always sent as well, which can be used to give a more detailed history or to spell out what has been said to the patient when this is relevant. The information can also be included in the standard text in the way Dr Hopkins suggests - for example, "The patient has/has not been told this diagnosis."

Dr Hopkins uses two anecdotes to support his prediction that many doctors could not be relied on to edit our summaries properly. If he is right it would be easier to spot their errors in our system because they would not be submerged in large chunks of text. The consultant can also keep an eye on the editing process on ward rounds and root out problems by using the audit facilities.

Our registrars do not do the typing themselves, as described by Dr M L Jenkinson and others. ${ }^{2}$ This might be more practicable when doctors also use computers routinely for other purposes, such as ordering tests. Our summaries, however, can also be updated and reprinted after a clinic visit (as well as after a ward round). This is a particularly useful feature, which is unique, as far as we know.

Our software system can be used in various ways, ranging from typing free text to choosing specific options if the standard text has been turned into a rigid research form. We are still exploring the possibilities. The best way to resolve questions of the kind raised by Dr Hopkins and Dr Jenkinson and colleagues is to set up proper studies to compare these different approaches.

D E HUW LLEWELYN

D L EWINS

JACKIE HORN

ALAN M MCGREGOR

Department of Medicine

King's College School of Medicine and Dentistry,

London SE5 8RX

TYRRELL G R EVANS

Paxton Green Health Centre,

London SE21 8AU

1 Llewelyn DEH, Ewins DL, Horn J, Evans TGR, McGregor AM. Computerised updating of clinical summaries: new opportunities for clinical practice and research? $\mathrm{Br}$ Med $\mathcal{J}$ 1988;297:1504-6. (10 December.)

2 Jenkinson ML, Pinkney JH, Pedoe DST. Computerised updating of clinical summaries. Br Med $\mathcal{J}$ 1989;298:257-8. (28 January.)

\section{Postoperative diabetes insipidus}

SIR, - The issue of the increased mortality which is associated with a very early onset of diabetes insipidus after suprasellar operations is not specifically addressed in the editorial on postoperative diabetes insipidus.' Prevention in this situation is all. Severe hypernatraemia necessitating vigorous treatment may put the patient at risk of cerebral venous thrombosis from water loss $^{2}$ and possibly central pontine myelinolysis from sudden large osmolar shifts. ${ }^{2}$ An overall mortality of $68 \%$ has been reported in hospital patients with severe hypernatraemia. ${ }^{4}$ Hourly measurement of urinary output and volume replacement for 72 hours as previously used by Seckl et al' should be routine for all patients to prevent the rapid onset of severe hypernatraemia. Serum sodium concentrations should also be monitored hourly as the most convenient index of plasma water, and a sodiumpotassium analyser on the ward may prove convenient. Weigh beds may also be useful in an ancillary role, particularly where urinary leakage from catheter drainage occurs or where there is a delay in receiving laboratory reports.

WILLIAM P TORMEY

Department of Chemical Pathology,

Beaumont Hospital,

Dublin 9, Ireland

I Seckl J, Dunger D. Postoperative diabetes insipidus. Br Med $\mathcal{J}$ 1989;298:2-3. (7 January.)

2 Lyen KR, Grant DB. Endocrine function, morbidity, an mortality after surgery for craniopharyngioma. Arch Dis Child 1982;57:837-41.

3 McKee AC, Winkelman MD, Banker BQ. Central pontine myelinolysis in severely burned patients: relationship to serum hyperosmolality. Neurology 1988;38:1211-7.

4 Hislop RM, Elder J, McLelland A, O'Reilly D StJ. Hypernatraemia: a three-year retrospective study. Ann Clin Biochem 1988;25:42-3s.

5 Seckl JR, Dunger DB, Lightman SL. Neurohypophyseal function during early postoperative diabetes insipidus. Brain 1987;110:737-46

SIR,-Drs Jonathan Seckl and David Dunger recommend a dose of $1-2 \mu \mathrm{g}$ desmopressin (DDAVP) intramuscularly in the management of established postoperative diabetes insipidus. In our experience many patients are sensitive to this agent so that doses as low as $0 \cdot 25 \mu \mathrm{g}$ intramuscularly may produce satisfactory antidiuresis for up to 12 hours. It is clearly important to use the lowest effective dose in this complex and changing situation, and we would therefore suggest that an initial test dose of $0.25 \mu \mathrm{g}$ should be given to assess clinical response in all patients with postoperative diabetes insipidus.

We agree that the metered intranasal spray preparation of desmopressin is useful for longer term treatment, but its applicability is reduced by the minimum dose delivered of $10 \mu \mathrm{g}$. It is thus of limited value in patients requiring intermediate doses. We hope that this point will be addressed by the manufacturers.

J P MONSON M I MCCARTHY

G C TOMS

Department of Metabolism and Endocrinology,

The London Hospital,

London E1 1 BB

1 Seckl J, Dunger D. Postoperative diabetes insipidus. Br Med $\mathcal{F}$ 1989;298:2-3. (7 January.)

\section{Prevention of diabetic nephropathy with enalapril}

SIR,-Dr Stephen Pickering and others' have drawn attention to our latest results, ${ }^{2}$ and their comments are also valid for the first part of our data, which was published in this journal one year ago." We would like to answer some of the questions they raise.

Seven of the patients we studied had initial systolic blood pressure above $140 \mathrm{~mm} \mathrm{Hg}$, but none had diastolic blood pressure above $90 \mathrm{~mm} \mathrm{Hg}$. Systolic blood pressure was not significantly higher in the group given enalapril than in the group given placebo (137 (SE 7) $v$ $132(5) \mathrm{mm} \mathrm{Hg}$ ) and diastolic blood pressure was almost identical (82 (8) $v 81(7) \mathrm{mm} \mathrm{Hg}$ ). Blood pressure is a variable with a continuous distribu tion; $160 / 95 \mathrm{~mm} \mathrm{Hg}$ and $140 / 90 \mathrm{~mm} \mathrm{Hg}$ are arbitrary (and still debated) thresholds given as references to be applied to a general population. Conversely, the main criterion for selection in our study was the persistence of microalbuminuria, an early sign for kidney damage due to diabetic glomerulopathy. As urinary albumin concentration is sometimes slightly increased in essential hypertension we used $160 / 95 \mathrm{~mm} \mathrm{Hg}$ as an exclusion criterion to avoid false diagnoses of incipient diabetic nephropathy. ${ }^{+}$The main message from our study, also supported by others, ${ }^{56}$ is that in incipient diabetic nephropathy blood pressure rises together with urinary albumin concentration even if initial blood pressure values were in the "normal" range.

Dr Pickering and his colleagues will notice in our first report that glomerular filtration rate rose significantly in the first six months that patients took enalapril. After discussion we speculated that this rise was attributable to the effects of the drug on renal vascular resistance. ${ }^{3}$ The absence of further increase in the next six months supports this contention. What seemed "harmful" to us was the small but significant decline in the glomerular filtration rate seen with placebo over one year ${ }^{2}$; we postulated on the basis of studies on rats that the fall in intraglomerular pressure (which may be present but cannot be investigated in patients given treatment) was beneficial.

We agree that a study on a small number of carefully selected patients must be confirmed by a large number of other observations on the effects of inhibition of angiotensin converting enzyme on the natural course of diabetic nephropathy, and not only on microalbuminuria.

MICHEL MARRE PHILIPPE PASS

Service de Diabétologie,

Hôpital Saint-Louis,

75475 Paris, France

Service d'Information Médicale

GILLES CHATELLIER

Hôpital de la Pitié-Salpêtrière,

75013 Paris

INSERM U35,

JOËL MENARD

S5005 Paris 